\title{
Adaptation to organic dust exposure: a potential role of L-selectin shedding?
}

\author{
E. Israël-Assayag, Y. Cormier
}

\begin{abstract}
Adaptation to organic dust exposure: a potential role of L-selectin shedding? E. IsraëlAssayag, Y. Cormier. (C) ERS Journals Ltd 2002.

ABSTRACT: Swine confinement workers, exposed to high levels of organic dust, present a high prevalence of respiratory symptoms but show only mild lung inflammation. This contrasts with the intense inflammatory response observed when naive subjects are exposed to the same environment. Shedding of L-selectin may regulate the recruitment of inflammatory cells and explain this discrepancy.

Soluble L-selectin (sL-selectin) levels were measured in sera of 36 workers, 35 control subjects and eight healthy volunteers briefly and repeatedly exposed to swine confinement buildings. White blood cell counts (WBC) and serum interleukin (IL)-6 levels were measured as markers of systemic inflammation.

Higher concentrations of sL-selectin were found in the sera of workers than in controls (1452 $\pm 62 \mathrm{ng} \cdot \mathrm{mL}^{-1}$ and $872 \pm 25 \mathrm{ng} \cdot \mathrm{mL}^{-1}$, respectively) whereas no differences were detected before and after acute repeated exposures of exposed volunteers. WBC were increased after exposure in exposed volunteers but not in workers. Both workers and exposed volunteers had increased IL-6 serum levels, although it was more pronounced for the exposed volunteers.

These results support the hypothesis that shedding of L-selectin may downregulate the inflammatory response to organic dust-contaminated environments and constitute one mechanism of adaptation to the farm environment.
\end{abstract}

Eur Respir J 2002; 19: 833-837.

Unité de recherche, Centre de pneumologie, Institut de cardiologie et de pneumologie, Hôpital Laval, Ste Foy, Québec, Canada.

Correspondence: Y. Cormier

Hôpital Laval

2725 Chemin Ste Foy

Ste Foy

Québec

Canada

G1V 4G5

Fax: 4186564762

E-mail: yvon.cormier@med.ulaval.ca

Keywords: Lung inflammation

soluble L-selectin

swine confinement workers

Received: November 142001

Accepted after revision January 92002
Swine confinement buildings (SCB) are heavily contaminated by organic dusts containing high levels of bacteria, fungi, endotoxins, and toxic gases [1, 2]. A brief exposure of healthy naive subjects to SCB results in an acute and intense pulmonary and systemic inflammatory response with an increase in neutrophils in blood, lung, and nasal cavities; other symptoms include fever, headaches and increased airway reactivity $[3,4]$. In contrast, SCB workers exposed daily to the same environment present a moderate infiltration of inflammatory cells in the lung and no acute reactions $[5,6]$. This observation could be explained by a selection process whereby sensitive individuals leave the work environment. This is however unlikely since all naive subjects develop an intense inflammatory response to SCB exposure; moreover, swine production units in most countries are family owned and operated, leaving little room for opting out of this work place. A more plausible explanation for this difference between SCB workers and naive subjects is an adaptation process. SCB workers in family farms are exposed daily to the environment, even on weekends, and seldom, if ever, take vacations. The adaptation process could be similar to what has been described previously for cotton workers, a phenomenon known as "Monday morning chest tightness" [7, 8], where chest tightness and decrease in lung functions observed upon re-exposure on Mondays waned over the following days.
The differences in response between SCB workers and naive subjects indicate that mechanisms limiting inflammatory responses must be present in SCB workers. Endotoxin is a major contaminant of SCB and it has been well documented that repeated exposure to endotoxin induces a state of tolerance against its own acute effects [9]. This mechanism of tolerance involves the downregulation of cell surface receptors essential for endotoxin signalling pathways [10] and the subsequent inhibition of inflammatory mediators.

Another potential mechanism of adaptation is the regulation of leukocyte recruitment to sites of inflammation. Migration of leukocytes from the systemic circulation to tissue involves an interaction between leukocytes and the vascular endothelium. This interaction is mediated by the expression of adhesion molecules on leukocyte surface and vascular epithelium $[11,12]$. Synthesis and expression of these molecules are regulated by a variety of inflammatory mediators [13]. L-selectin (CD62L), a cell adhesion molecule expressed by most leukocytes, plays a key role in the initiation of leukocyte capturing and rolling on the activated endothelium and thus leukocyte migration to sites of inflammation [14, 15]. Following activation, the extracellular portion of the molecule is shed from the cell surface and enters the blood circulation. Shedding of L-selectin regulates leukocyte rolling velocity in vivo [16]. Moreover, leukocytes 
from L-selectin-deficient mice have an impaired homing and migration capacity [17]. A recent study has shown that inhibition of L-selectin shedding increases leukocyte adhesion and migration [18] through the endothelium, indicating the important role of L-selectin shedding in the downregulation of leukocyte recruitment at sites of inflammation.

Since SCB workers develop a milder inflammatory response to their environment than acutely exposed healthy naive subjects, and since soluble L-selectin (sL-selectin) decreases inflammatory cell migration, the authors hypothesized that SCB workers may have increased levels of sL-selectin. This mechanism could explain the adaptation process to SCB and potentially other organic dust contaminated environments. To investigate this hypothesis, serum levels of sL-selectin were measured in SCB workers and nonexposed control subjects and in the serum of healthy volunteers before and after a repeated 4-h exposure to SCB. White blood cell (WBC) counts and serum interleukin (IL)-6 concentrations were measured as markers of systemic inflammation.

\section{Material and methods}

The study population consisted of 36 nonsmoking male workers (age 18-55) and 35 sex- and agematched nonsmoking controls recruited from hospital employees. These employees represented a whole range of professions from doctors to desk clerks and maintenance people. Workers spent at least $2 \mathrm{~h} \cdot \mathrm{day}^{-1}$ in the SCBs and had been employed in the industry for at least 2 yrs. Workers and controls had no medical history of chronic diseases, were not on any medication, and had no signs of recent viral or bacterial infection (at least 1 month). Workers were selected from a list of producers provided by the farmer's union. They were contacted by phone and asked to participate. All those solicited accepted. The workers were then visited by a research nurse, and an informed consent form, approved by the ethics committee of the authors institution, was signed. Controls also signed an approved informed consent. Blood samples were taken from both the workers and controls in the morning between 08:00-10:00 h. Blood samples were kept on ice until processing, which was done within $2 \mathrm{~h}$ of withdrawal. Sera were frozen at $-70^{\circ} \mathrm{C}$ until analysis for sL-selectin and IL-6 levels.

For the acute exposure experiments, sera from subjects involved in a previous study [3] were analysed. In this protocol, eight healthy nonsmoking and nonatopic male volunteers (age 23-28) never exposed previously to SCB spent $4 \mathrm{~h}$, at 1 -week intervals in seven different SCB. This time sequence was justified by the results of previous studies that showed that the effects of acute exposure were shortlived [19]. Forced expiratory volume in one second (FEV1), provocative concentration causing a $20 \%$ fall in FEV1 and forced vital capacity values were measured before each re-exposure to confirm that they returned to baseline values. The sera were aliquoted and kept at $-70^{\circ} \mathrm{C}$. Blood was collected in the afternoon on the day of pre-exposure and at the same time $2 \mathrm{~h}$ after each SCB exposure. All exposed volunteers signed an informed consent approved by the ethics committee.

Total and differential blood cell counts were obtained electronically with a cell counter STKS (Coulter Electronics Ltd, Hialeah, FL, USA) and serum levels of sL-selectin and IL-6 were measured by enzyme-linked immunosorbent assay (ELISA) using commercial kits (R\&D systems Inc, Minneapolis, MN, USA).

\section{Statistical analysis}

Mean \pm SEM were determined for continuous variables. Two analyses were performed on the data. Firstly, comparison between controls and workers. The statistical analysis used was a one-way analysis of variance (ANOVA) with a factor representing the group effect (the comparison between the two groups). The second analysis compared workers at baseline and after seven exposures. A repeated design with sphericity tests was used to analyse the data. Comparisons were performed a posteriori using Tukey's method. The results were considered significant if $\mathrm{p} \leqslant 0.05$.

\section{Results}

Workers chronically exposed to SCB had normal WBC counts, similar to controls and a slight but borderline significant increase in IL-6 ( $\mathrm{p}=0.05)$ (fig. 1). Serum levels of sL-selectin were significantly higher in workers than in the controls $\left(1452 \pm 62 \mathrm{ng} \cdot \mathrm{mL}^{-1}\right.$ versus $872 \pm 25 \mathrm{ng} \cdot \mathrm{mL}^{-1}, \mathrm{p}<0.0001$ ) (fig. 2).

Exposed volunteers showed a significant increase in WBC $(\mathrm{p}<0.0001)$ and serum IL-6 $(\mathrm{p}=0.0009)$ after each short-term exposure compared to baseline levels (fig. 3). No differences in SL-selectin levels were observed between baseline levels and after repeated short-term exposure of naive volunteers to SCB (fig. 4, $\mathrm{p}=0.296$ ). Determination of the serum values of IL-6 and sL-selectin in the exposed volunteers was carried out on a separate day and with different assay kits than the other two groups.

\section{Discussion}

In this study, no air analysis was performed in the SCB visited, however in previous studies the authors sampled and analysed the air of several SCB in the Quebec region. and showed that all SCB were similarly harmful to naive exposed volunteers [19]. Thus, the assumption can be made that most SCB in this region have a poor air quality. The present study shows that long-term exposure to swine dust is associated with high levels of SL-selectin, no increase in WBC and a slight increase in IL-6. In contrast, short-term exposures are not associated with increased levels of sL-selectin; if anything, the trend was to lower levels. As reported here and shown in many previous studies, short-term exposures of naive subjects to 

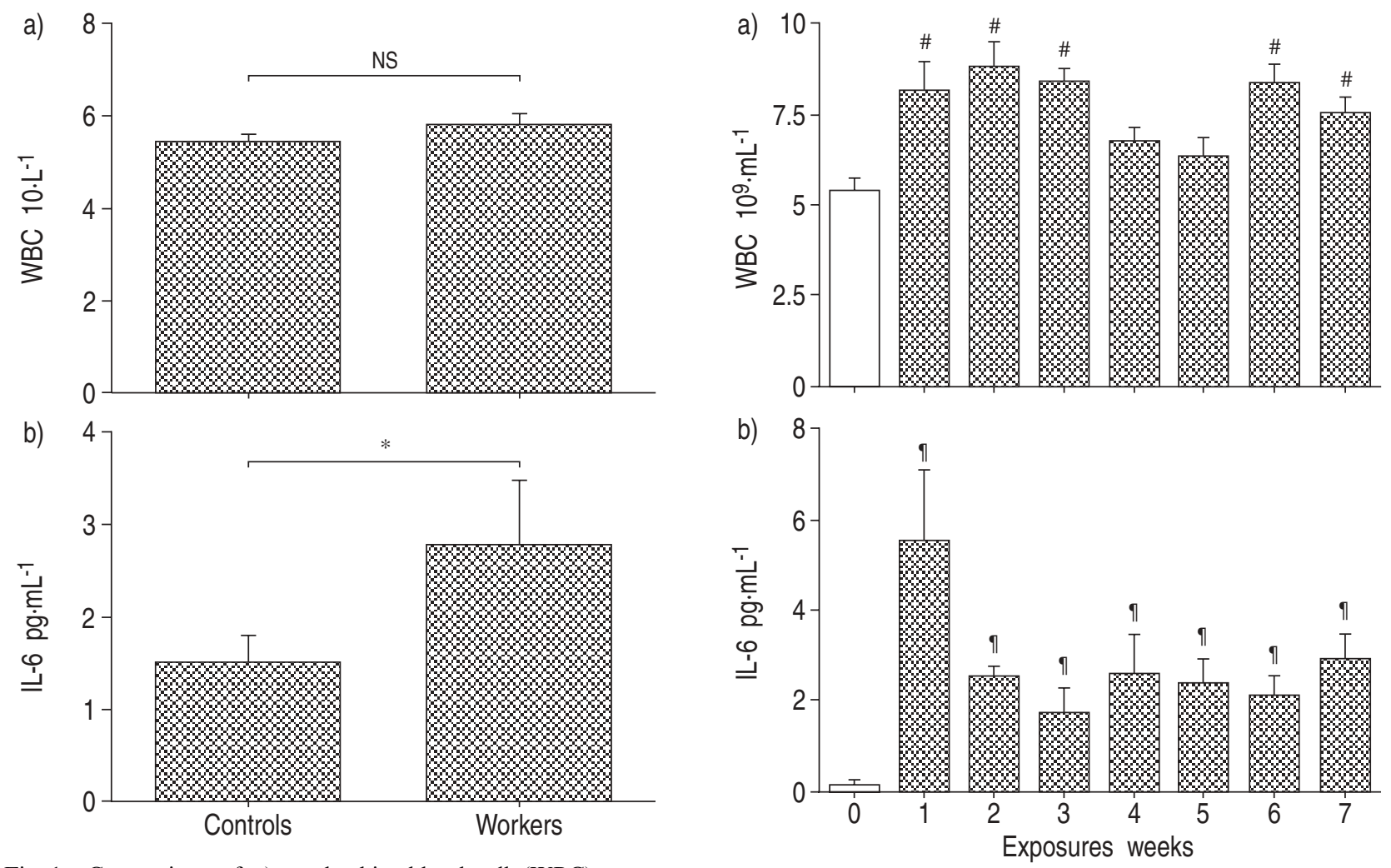

Fig. 1.-Comparison of a) total white blood cell (WBC) counts and b) serum interleukin (IL)- 6 concentrations from control subjects (controls, $\mathrm{n}=35$ ) and swine confinement building workers (workers, $n=36$ ). *: $\mathrm{p}=0.05$.

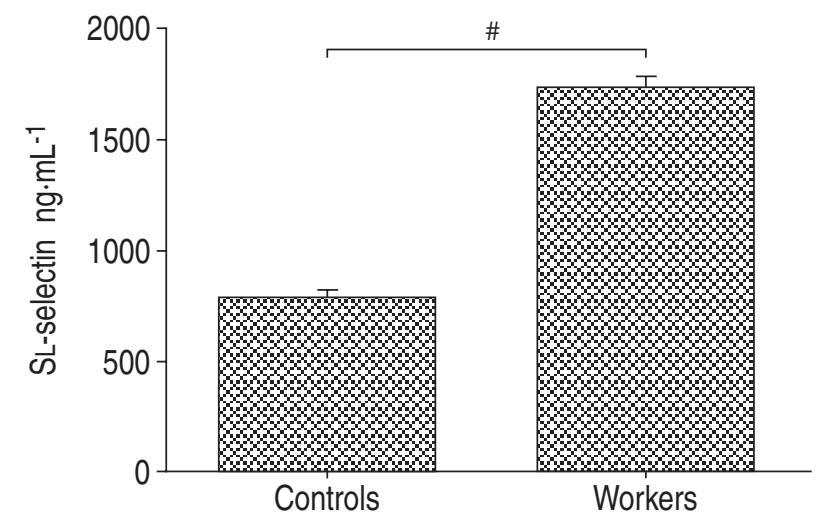

Fig. 3.-Comparison of a) total white blood cell counts (WBC) and b) serum interleukin (IL)-6 concentrations from eight healthy exposed volunteers before ( $\square$ ) and after seven 4-h weekly exposures to swine confinement buildings (四). ${ }^{\#}: \mathrm{p} \leqslant 0.0001$; " $\mathrm{p}=0.0009$.

exposed volunteers and the other two groups. Changes in exposed volunteers before and after exposures to SCB and differences between workers and controls are only compared here.

The authors believe that the difference in response to SCB exposure between workers and controls can be explained, at least in part, by the levels of sL-selectin in the blood circulation. Shedding of membranebound L-selectin occurs after leukocyte activation.

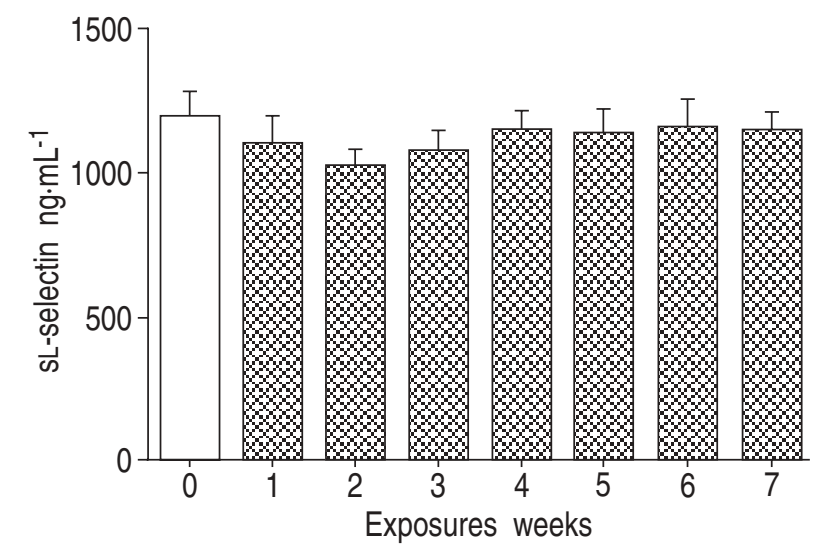

Fig. 2. - Concentration of soluble L-selectin in serum from control subjects (controls, $\mathrm{n}=35$ ) and swine confinement building workers (workers, $\mathrm{n}=36$ ). ${ }^{\#}: \mathrm{p}<0.0001$.

SCB induces an increase in peripheral $\mathrm{WBC}$ and high levels of serum IL-6 and markedly enhances the number of neutrophils in the nasal passages and the lungs $[3,20]$, whereas, although not measured here, workers do not show intense lung cellular infiltrations [5, 6]. The differences in sL-selectin concentrations observed between controls and exposed volunteers may be due to differences in the number of individuals (35 versus eight), the time of blood collection (morning versus afternoon), and the fact that the assays were performed on different days. Therefore, no comparison can be made between

Fig. 4. - Concentration of soluble L-selectin in serum from eight healthy exposed volunteers before ( $\square$ ) and after seven 4-h weekly exposures to swine confinement buildings $(\mathbf{D})$. 
As mentioned in the introduction, the mechanisms by which sL-selectin down-modulates inflammation are not fully elucidated. Soluble L-selectin could compete with membrane-bound L-selectin, thus diminishing leukocyte adhesion to the endothelium and consequently preventing their migration.

Bacterial endotoxin (LPS), a major contaminant of $\mathrm{SCB}$, induces lung inflammation in healthy subjects $[20,21]$. It has also been reported that the decline in pulmonary function among workers [22] is associated with levels of LPS in the SCB environment. LPS is known to activate inflammatory cells, increase the production of inflammatory cytokines and chemokines in the lung and is a potent chemoattractant for neutrophils [8]. LPS is also known to down-modulate L-selectin expression on the cell surface of polymorphonuclear cells [23-24], and to induce shedding of the molecule in a dose-dependent manner. In this study, the high levels of serum L-selectin found in workers may be a consequence of continuous LPS exposure and constitute a mechanism of LPS tolerance that could explain the adaptation of these workers to their work environments and further support the antiinflammatory role of sL-selectin. Further studies are needed to see if workers exposed to other organic dust contaminated environments develop similar potentially protective mechanisms. Since swine production in most countries is evolving from traditional family operated units, where workers spend a few hours per day, every day, to that of large scale productions, where workers work for 4 or 5 8-h days and have days off, it will be interesting to see if modern workers will be able to adapt to their workplace. The off days could result in a loss of the adaptation and produce similar symptoms as the "cotton dust Monday morning fever" when they return to work after their days off.

In conclusion, this study suggests a novel biological mechanism for swine confinement building workers adaptation to an organic dust-contaminated workplace. The findings of this study could be applicable to a wide range of similar work environments including dairy barns, sewage processing plants, metal fluid using workshops, cotton transforming industry, fish plants, peat moss factories, sawmills, pulp and paper mills, etc. The hypothesis that adaptation may be lost, or at least be less efficient, when work conditions permit days off from exposure to contaminated environments is also raised here.

\section{References}

1. Clark S, Rylander R, Larsson L. Airborne bacteria, endotoxin and fungi in dust in poultry and swine confinement buildings. Am Ind Hyg Assoc J 1983; 44: 537-541.

2. Cormier Y, Tremblay G, Mériaux A, Brochu G, Lavoie J. Airborne microbial contents in two types of swine confinements buildings in Quebec. Am Ind Hyg Assoc J 1990; 51: 304-309.

3. Cormier Y, Duchaine C, Israel-Assayag E, Bedard G, Laviolette M, Dosman J. Effects of repeated swine building exposures on normal naive subjects. Eur Respir J 1997; 10: 1516-1522.

4. Wang Z, Manninen A, Malmberg P, Larsson K. Inhalation of swine-house dust increases the concentrations of interleukin-1 beta (IL-1 beta) and interleukin-1 receptor antagonist (IL-1ra) in peripheral blood. Respir Med 1998; 92: 1022-1027.

5. Larsson K, Eklund A, Malmberg P, Belin L. Alterations in bronchoalveolar lavage fluid but not in lung function and bronchial responsiveness in swine confinement workers. Chest 1992; 101: 767-774.

6. Pedersen B, Iversen M, Bundgaard Larsen B, Dahl R. Pig farmers have signs of bronchial inflammation and increased numbers of lymphocytes and neutrophils in BAL fluid. Eur Respir J 1996; 9: 524-530.

7. Morgan KC. Byssinosis and related conditions in Occupational Lung Diseases. In: Morgan KC, Seaton A, eds. Philadelphia, B. Saunders, 1975; pp. 274-288.

8. Morrison DC, Ryan JL. Endotoxins and disease mechanisms. Annu Rev Med 1987; 38: 417-432.

9. Medvedev AE, Kopydlowski KM, Vogel SN. Inhibition of lipopolysaccharide-induced signal transduction in endotoxin-tolerized mouse macrophages: dysregulation of cytokine, chemokine, and toll-like receptor 2 and 4 gene expression. J Immunol 2000; 164: 5564 5574.

10. Rylander R. Health effects of cotton dust exposures. Am J Ind Med 1996; 29: 33-40.

11. Albelda SM, Smith CW, Ward PA. Adhesion molecules and inflammatory injury. Faseb J 1994; 8: 504 512.

12. Springer TA. Traffic signals on endothelium for lymphocyte recirculation and leukocyte emigration. Annu Rev Physiol 1995; 57: 827-872.

13. Meager A. Cytokine regulation of cellular adhesion molecule expression in inflammation. Cytokine Growth Factor Rev 1999; 10: 27-39.

14. Gallatin WM, Weissman IL, Butcher EC. A cellsurface molecule involved in organ-specific homing of lymphocytes. Nature 1983; 304: 30-34.

15. Tedder TF, Steeber DA, Pizcueta P. L-selectindeficient mice have impaired leukocyte recruitment into inflammatory sites. J Exp Med 1995; 181: 22592264.

16. Hafezi-Moghadam A, Ley K. Relevance of L-selectin shedding for leukocyte rolling in vivo. J Exp Med 1999; 189: 939-948.

17. Arbones ML, Ord DC, Ley K, et al. Lymphocyte homing and leukocyte rolling and migration are impaired in L-selectin-deficient mice. Immunity 1994; 1: 247-260.

18. Hafezi-Moghadam A, Thomas KL, Prorock AJ, Huo Y, Ley K. L-selectin shedding regulates leukocyte recruitment. $J$ Exp Med 2001; 193: 863-872.

19. Duchaine C, Grimard Y, Cormier Y. Influence of building maintenance, environmental factors, and seasons on airborne contaminants of swine confinement buildings. AIHAJ 2000; 61: 56-63.

20. Wang Z, Malmberg P, Larsson P, Larsson BM, Larsson K. Time course of interleukin-6 and tumor necrosis factor-alpha increase in serum following inhalation of swine dust. Am J Respir Crit Care Med 1996; 153: 147-152.

21. Sandstrom T, Bjermer L, Rylander R. Lipopolysaccharide (LPS) inhalation in healthy subjects increases neutrophils, lymphocytes and fibronectin levels in 
bronchoalveolar lavage fluid. Eur Respir J 1992; 5: 992-996.

22. Vogelzang PF, van der Gulden JW, Folgering H, et al. Endotoxin exposure as a major determinant of lung function decline in pig farmers. Am J Respir Crit Care Med 1998; 157: 15-18.

23. Crockett-Torabi E, Sulenbarger B, Smith CW,
Fantone JC. Activation of human neutrophils through L-selectin and Mac-1 molecules. J Immunol 1995; 154: 2291-2302.

24. Lipton BP, Bautista AP, Delcarpio JB, McDonough KH. Effects of endotoxin on neutrophil-mediated I/R injury in isolated perfused rat hearts. Am $J$ Physiol Heart Circ Physiol 2001; 280: H802-H811. 